\title{
Associations of mental disorders and neurotropic parasitic diseases: a meta- analysis in developing and emerging countries
}

Labanté Outcha Daré1* (D), Pierre-Emile Bruand², Daniel Gérard², Benoît Marin', Valerie Lameyre', Farid Boumédiène $e^{1}$ and Pierre-Marie Preux ${ }^{1}$

\begin{abstract}
Background: Although they are declining worldwide, neurotropic parasitic diseases are still common in developing and emerging countries. The aim of this study was to estimate the pooled prevalence and pooled association measures of comorbidities between mental disorders (anxiety, depression, bipolar disorder, and schizophrenia) and neurotropic parasitic diseases (malaria, cysticercosis, toxoplasmosis, human African trypanosomiasis, Chagas disease, and human toxocariasis) in developing and emerging countries.

Methods: As the first meta-analysis on this topic, this study was performed in accordance with PRISMA guidelines. The protocol was registered in PROSPERO ( $N^{\circ}$ CRD42017056521). The Medline, Embase, Lilacs, and Institute of Epidemiology and Tropical Neurology databases were used to search for articles without any restriction in language or date. We evaluated the quality of studies independently by two investigators using the Downs and Black assessment grid and pooled estimates using the random-effects method from CMA (Comprehensive Meta Analysis) Version 3.0.

Results: In total, 18 studies published between 1997 and 2016 met our inclusion criteria. We found that the prevalence of anxiety and depression in people suffering from Chagas disease and/or neurocysticercosis was $44.9 \%$ (95\% Cl, 34.4-55.9). In 16 pooled studies that included 1782 people with mental disorders and 1776 controls, toxoplasmosis and/or toxocariasis were associated with increased risk of schizophrenia and/or bipolar disorders (odds ratio $=2.3 ; 95 \% \mathrm{Cl}, 1.7-3.2$ ). Finally, toxocariasis and/or toxoplasmosis were associated with an increased risk of the onset of schizophrenia (odds ratio $=2.4 ; 95 \% \mathrm{Cl}, 1.7-3.4$ ).

Conclusion: Our pooled estimates show that the associations between diseases studied are relatively high in developing and emerging countries. This meta-analysis supports the hypothesis that toxoplasmosis could be the cause of schizophrenia. These findings could prove useful to researchers who want to further explore and understand the associations studied.
\end{abstract}

Keywords: Meta-analysis, Association, Co-morbidities, Mental disorders, Neurotropic parasitic diseases

\footnotetext{
* Correspondence: outcha_dare1986@yahoo.com

'INSERM, CHU Limoges, UMR_S 1094, Tropical Neuroepidemiology, University of Limoges, Institute of Neuroepidemiology and Tropical Neurology, CNRS FR 3503 GEIST, F-87000 Limoges, France

Full list of author information is available at the end of the article
}

(c) The Author(s). 2019 Open Access This article is distributed under the terms of the Creative Commons Attribution 4.0 International License (http://creativecommons.org/licenses/by/4.0/), which permits unrestricted use, distribution, and reproduction in any medium, provided you give appropriate credit to the original author(s) and the source, provide a link to the Creative Commons license, and indicate if changes were made. The Creative Commons Public Domain Dedication waiver (http://creativecommons.org/publicdomain/zero/1.0/) applies to the data made available in this article, unless otherwise stated. 


\section{Background}

Although parasitic diseases are declining, they are still common in developing and emerging countries. Among the public health issues typically faced by developing and emerging countries (all non high income countries according to World Bank rankings) [1], neurotropic parasitic diseases are very common [2]. Neurotropic parasitic diseases such as malaria, cysticercosis, toxoplasmosis, human African trypanosomiasis (HAT), Chagas disease, and human toxocariasis have a predilection for infesting the central nervous system, which can lead to neurological disorders. Similarly, mental disorders are frequent with pooled 12-month period prevalence estimates of $17.6 \%(15.5-20.0 \%)$ in low and middle-income countries [3]. However, there are few studies regarding the association of mental disorders with neurological parasitoses in these countries.

To date, epidemiological studies have identified several risk factors for the different disease groups studied [49]. The table below (Table 1) provides a summary of the main risk factors of interest diseases in this metaanalysis. We have focused our attention on parasitic diseases due to the ever-present burden of these diseases in developing and emerging countries, and we selected the diseases according to their overall burden [5, 11-13]. It is estimated that mental disorders rank third among the most frequent diseases encountered in the world, just after cancer and cardiovascular diseases [14].

In developing and emerging countries, surveys have suggested that more than $25 \%$ of individuals in their lifetime develop one or more mental or behavioural disorders [15]. In the general population, it has been estimated that $3 \%$ of people are affected by severe depression, $2 \%$ by generalized anxiety disorders and $1 \%$ by

Table 1 Risk factors of interest diseases

\begin{tabular}{ll}
\hline Disease & Risk factor \\
\hline Mental disorders & - Family history \\
& - Stressful living conditions \\
& - Existence of a chronic disease \\
& - Traumatisms \\
& - Drug use \\
& - Child abuse or neglect and/or \\
& lack of social support [4, 5] \\
& \\
Neurotropic parasitic diseases & \\
Human African Trypanosomiasis & - Family history of HAT, living near \\
(HAT) & a wetland [6] \\
Chagas disease & Economic, cultural, and human \\
& behaviour [7] \\
Cysticercosis & Age, home, consumption of \\
Toxoplasmosis & undercooked meat, and \\
Human Toxocariasis & unwashed fruit or raw \\
& vegetables [8] \\
& Bare hand contact with the \\
& ground or injury to animals, \\
& consumption of poorly \\
& washed vegetables [10] \\
\hline
\end{tabular}

schizophrenia [16]. Parasitic diseases remain a major burden to developing and emerging countries, although this type of disease has declined globally. In 2015, out of 95 countries and territories in the world where malaria transmission remains high, it is estimated that the number of malaria cases was 214 million (95\% CI, 149-303) and that malaria is responsible for 438,000 deaths per year $(95 \%$ CI, 236000-635,000) mainly in Africa (88\%) [17]. In 2012, eight million individuals were already infected with Trypanosoma cruzi, the parasite that causes Chagas disease, in endemic areas of 21 Latin American countries. In addition, the chronic infection caused by this parasite is incurable, can be disabling, and causes more than 10,000 deaths per year [18]. The seroprevalence of toxocariasis varies from 2.4 to $30.0 \%$ in Europe [19], but in tropical countries, higher prevalences have been reported: 7.5 to $92.8 \%$ in Africa [20, 21], 6.4 to $52.0 \%$ in South America [22, 23], and 5.0 to $84.6 \%$ in Asia $[24,25]$. Human African trypanosomiasis (HAT) affects 60 million inhabitants mainly living in rural areas of 36 endemic sub-Saharan countries in East, West and Central Africa [26]. Toxoplasmosis remains frequent in these countries and even in developed countries [10]. Finally, the agent responsible for cysticercosis, Taenia solium, is found mainly in Latin America, Asia, subSaharan Africa, and the Indian Ocean region. According to the World Health Organization (WHO), cysticercosis is responsible for 50,000 deaths per year with 2.5 to 5 million adult worm carriers and 50 million cysticercal larvae carriers [27, 28]. Neurocysticercosis, a type of brain damage resulting from cysticercosis, is thought to be a factor responsible for more than $50 \%$ of late onset epileptic seizures in developing countries [27].

In recent years, there has been an increasing number of studies on co-morbidities between mental disorders and parasitic diseases, particularly those with neurological tropism such as toxoplasmosis [9], human toxocariasis [29, 30], and cysticercosis [31-34]. However, these have produced heterogenous data and to date, no meta-analysis has been published on the association of mental disorders and parasitic diseases in developing and emerging countries; hence the reason why we decided to perform this study.

\section{Purpose of the study}

The purpose of this study was to estimate the pooled prevalence and pooled association measures of comorbidities between mental disorders and neurotropic parasitic diseases in developing and emerging countries.

\section{Methods}

To perform this meta-analysis, the diseases of interest are neutropic parasitic diseases: malaria, cysticercosis, toxoplasmosis, HAT, Chagas disease, and human toxocariasis 
$[9,13]$. These are forms of parasitosis that have a predilection for infesting the central nervous system and which can result in neurological disorders. Mental disorders of interest were the same as those investigated in the previous meta-analysis [35]. These disorders interfere with thinking, feeling, mood, communication and daily functioning, which typically lead to a reduction in the ability to perform common daily activities, such as caring for family or working [4]. These were: anxiety, depression, bipolar disorder and schizophrenia $[5,11]$.

Since this meta-analysis is the continuation of a previously published study on the association of mental disorders and chronic physical diseases in developing and emerging countries, its shares the same research strategy, inclusion criteria and selection of articles, data extraction, article quality assessment and statistical analysis as our previous meta-analysis [35].

The protocol for this meta-analysis was recorded in PROSPERO ( $\mathrm{N}^{\circ}$ CRD42017056521) and accessible via the following link: http://www.crd.york.ac.uk/PROSPERO. This meta-analysis follows the recommended methodology for the meta-analysis of observational studies [36] and was performed in accordance with Preferred Reporting Items for Systematic Review and MetaAnalysis (PRISMA) guidelines [37].

The search for articles was conducted through four databases: Medline, Embase, Lilacs, and IENT (database of the Institute of Epidemiology and Tropical Neurology of the University of Limoges in France: http://www-ient.unilim.fr/) by LOD, the principal investigator, from February to May 2017 without linguistic or date restrictions.

The same research equation built on Medline below and used for the previous meta-analysis [35] was used in the other databases to search for articles in each of the 139 countries studied:

"("Depressive Disorder"[Mesh] OR "Depression" [Mesh]
OR "Anxiety Disorders"[Mesh] OR "Anxiety" [Mesh]
OR "Bipolar Disorder"[Mesh] OR
"Schizophrenia"[Mesh]) AND ("Diabetes
metillus"[Mesh] OR "Obesity"[Mesh] OR
"Neoplasms"[Mesh] OR "Cardiovascular
Diseases"[Mesh] OR "Pulmonary Disease, Chronic
Obstructive"[Mesh] OR "Malaria"[Mesh] OR
"Cysticercosis"[Mesh] OR "Toxoplasmosis"[Mesh] OR
"Toxocariasis"[Mesh] OR "Trypanosomiasis"[Mesh] OR
"Chagas Disease"[Mesh]) AND ("Name of a
country"[Mesh])." [35]

When searching for articles in the IENT database, which is specifically dedicated to work on neurotrophic parasitosis in the countries of interest of this study, only the free text terms "comorbidity" or "mental health comorbidity" were used. Finally, the registration and selection of articles was done through the Zotéro software.

Every article included in this meta-analysis had to meet the same criteria as the previous meta-analysis, which were: " be an original article whose full text was available; be a cross-sectional or analytical study; have been conducted on adult patients, both males and females, and on all age groups (age $\geq 15$ years); be a study involving either only hospitalised subjects or only nonhospitalised subjects, but not both hospitalised and nonhospitalised subjects at the same time; specify the method of disease diagnosis. For cross-sectional studies, it had to give the prevalence, or the data from which it could be calculated, and for analytical studies, it had to give the association measures or the data from which they could be calculated. " [35].

As in the previous meta-analysis [35], the revised Downs and Black evaluation grid was used independently $[38,39]$ by two researchers (LOD and PEB) to assess the quality of the studies included in this metaanalysis and the data were extracted for each article by LOD, the principal investigator. The statistical tests were performed with a significance threshold of $5 \%$ using Comprehensive Meta-Analysis (CMA) Version 3.0 [40]. Q-test and $I^{2}[41,42]$ were performed to assess the heterogeneity of the studies included in our pooled estimates. The DerSimonian-Laird random effects technique [43] was then used to calculate the pooled estimates and the results obtained were presented in forest plot. In order to investigate publication bias, we constructed a funnel plot and performed a Duval and Tweedie adjustment and filling test [43], and, Egger regression [44]. The robustness of our results was tested using the sensitivity test, which consisted of subtracting the study with the highest weight among the studies included in a pooled estimate and subtracting the lowest quality studies among the studies from a pooled estimate. Finally, we conducted subgroup analyses for the variables: original disease, associated disease, type of subject and continent.

\section{Results \\ General results}

Out of the 2604 different articles in English, French, Spanish, Portuguese, Chinese, and Russian, initially identified for co-morbidities between mental health and chronic physical diseases, and for co-morbidities between mental health and neurotropic parasitic diseases, 18 articles were included in our meta-analysis (Fig. 1). Among these 18 articles of co-morbidity studies on mental disorders and neurotropic parasitic diseases [4562] published between 1997 and 2016 and meeting our inclusion criteria, two were prevalence studies in individuals with neurotropic parasitic diseases who were 


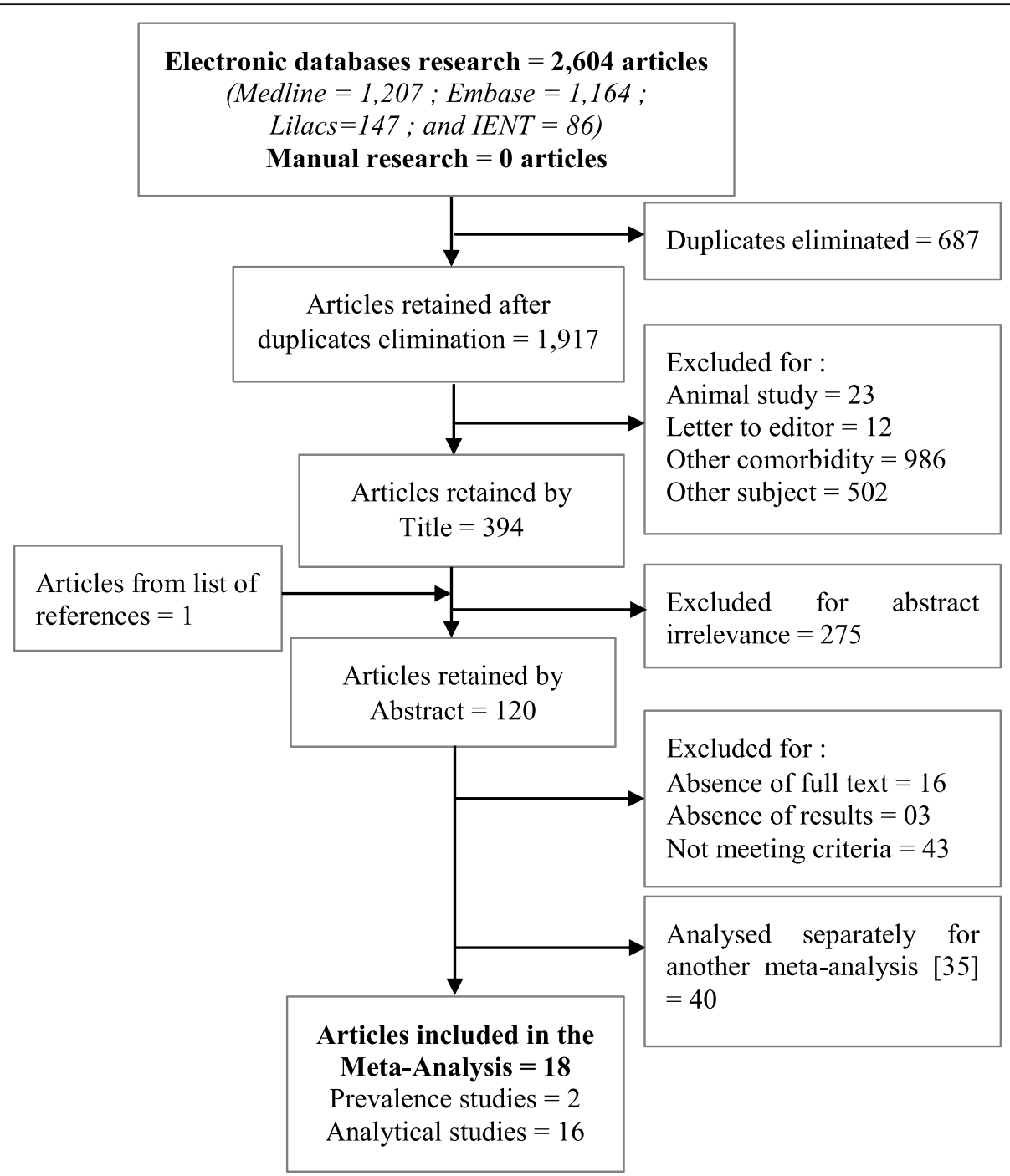

Fig. 1 Research strategy flow chart for the meta-analysis of associations of mental disorders and neurotropic parasitic diseases in developing and emerging countries

screened for mental disorders, and sixteen were analytical studies in individuals with mental disorders who were screened for neurotropic parasitic diseases (Table 2 and Table 3).

In the prevalence studies examined in this metaanalysis, the female to male sex ratio was 1.1 and the mean age was $43.9 \pm 7.5$ years. In the analytical casecontrol studies, the female to male sex ratio was 0.7 , while the mean age was $36.0 \pm 11.0$ years for cases, and $37.6 \pm 10.5$ years for controls. In the 18 analytical studies conducted, 11 were hospitalised patients. Nonhospitalised patients were studied in two prevalence studies and in the 7 remaining analytical studies. With the Downs and Black assessment grid, the mean quality score for the prevalence studies was found to be $18.5 \pm 2$ (maximum score of 22), while the mean for the case-control studies was found to be $16.4 \pm 3.1$ (maximum score of 25) (Additional file 1: Table S1 and Additional file 2: Table S2).

\section{Main findings}

In the prevalence studies, the diseases found were anxiety and/or depression for mental disorders, and Chagas disease and neurocysticercosis for neurotropic parasitic diseases. There were 16,610 subjects enrolled in these studies. The prevalence of depression in the 148 individuals with Chagas disease and neurocysticercosis was 44.9\% (95\% CI, 34.4-55.9) (Fig. 2). With regard to neuotropic parasitic diseases, toxoplasmosis and toxocariasis were found. In the 16 pooled studies that included 1782 people with schizophrenia and/or bipolar disorders, and 1776 controls. Mental disorders (schizophrenia and/or bipolar disorders) were associated with an increased risk 
Table 2 Characteristics of prevalence studies of associations of mental disorders and neurotropic parasitic diseases

\begin{tabular}{|c|c|c|c|c|c|c|c|c|c|}
\hline Reference & Continent & Subjects type & Original disease & Associated disease & Positive (n) & Total $(\mathrm{N})$ & $\begin{array}{l}\text { Diagnostic } \\
\text { method }\end{array}$ & F/M & $\begin{array}{l}\text { Average } \\
\text { age }\end{array}$ \\
\hline $\begin{array}{l}\text { Ozaki et al. [61] } \\
\text { Qual Life Res, } 2011\end{array}$ & Asia & Non-hospitalised & Chagas disease & $\begin{array}{l}\text { Anxiety and } \\
\text { Depression }\end{array}$ & 45 & 110 & $\mathrm{BDI}$ & $56 / 54$ & $51 \pm 13$ \\
\hline $\begin{array}{l}\text { Forlenza et al. [52] } \\
\text { J Neurol Neurosurg } \\
\text { Psychiatry, } 1997\end{array}$ & America & Non-hospitalised & Neurocysticercosis & Depression & 20 & 38 & $\begin{array}{l}\text { PSE; MMSE; } \\
\text { SADS-L; MSE }\end{array}$ & $20 / 18$ & 36.7 \\
\hline
\end{tabular}

Description of data:

$B D I$ Beck Depression Inventory, PSE Present State Examination, MMSE Mini Mental State Examination, SADS-L Schedule for Affective Disorders and SchizophreniaLifetime, MSE Mental Status Examination, F Female, M Male, Age in years

of toxoplasmosis and/or toxocariasis (odds ratio $=2.3$; 95\% CI, 1.7-3.2) (Fig. 3).

The distribution of the pooled studies was illustrated using a funnel plot. Based on Duval and Tweedie's "trim and fill" visual method, we found that 2 analytical studies were missing (Fig. 4). Afterwards, we found that the intercept result obtained by the Egger test was 2.4 (95\% CI, $-0.5-5.3 / p=0.09)$, which confirms the existence of publication bias.

From the included analytical studies, we found that the pooled odds ratio of the association of schizophrenia and/or bipolar disorders and toxoplasmosis and/or toxocariasis in cases (people with mental disorders) versus controls after sensivity analyses did not changes. It varied from 2.3 (95\% CI, 1.7-3.2) to 2.3 (95\% CI, 1.7-3.3) when the study with the greatest weight, Esshili et al. [51], was withdrawn. And it became 2.2 (95\% CI, 1.6-3.1) when Cetinkaya et al. [48] and Hamidinejat et al. [53], the studies with the lowest quality scores, were withdrawn.

Analysis of the selected subgroups by type of disease investigated, type of associated disease, type of subjects included, and continent allowed us to show the following findings: the odds ratio of the association between schizophrenia and toxocariasis was 2.7 (95\% CI, 1.1-7.0) in people with schizophrenia compared to the control group. And the association between mental disorders (schizophrenia and/or bipolar disorders) with toxoplasmosis was 2.3 (95\% CI, 1.7-3.2) in people with schizophrenia and/or bipolar disorders compared to the control group. For the association between schizophrenia and neurotropic parasitic diseases (toxocariasis and/ or toxoplasmosis) the odd ratio was 2.4 (95\% CI, 1.73.4). Co-morbidities between mental disorders (schizophrenia and/or bipolar disorders) and neurotropic parasitic diseases (toxoplasmosis and/or toxocariasis) had closely similar odds ratios in both hospitalised and nonhospitalised people. The odds ratio was 2.3 (95\% CI, 1.5-3.3) for the association between mental disorders (schizophrenia and/or bipolar disorders) and neurotropic parasitic diseases (toxoplasmosis and/or toxocariasis) when comparing cases with schizophrenia and/or bipolar disorders and controls. It was 2.5 (95\% CI, 1.4-4.4) for the association between mental disorders (schizophrenia and/or bipolar disorders) and toxoplasmosis when comparing cases with schizophrenia and/or bipolar disorders and controls (Fig. 5). Finally, the subgroup analysis by continent showed that in Asia, the odds ratio of comorbidities between mental disorders (schizophrenia and/or bipolar disorders) and neurotropic parasitic diseases (toxoplasmosis and/or toxocariasis) was 2.3 (95\% CI, 1.6-3.3).

\section{Discussion}

We focused on developing and emerging countries studied due to their high burden in the selected diseases. For mental disorders, these were anxiety, depression, bipolar disorder, and schizophrenia $[5,11]$ and for parasitic diseases with neurological tropism, these were malaria, cysticercosis, toxoplasmosis, HAT, Chagas disease, and human toxocariasis $[9,13]$.

In general, the diagnosis of diseases in the studies selected in this meta-analysis was performed using acceptable diagnostic techniques. Indeed, the quality of diagnostic techniques used to screen for mental disorders has been developed in accordance with DSM-5 and ICD-10 [63]. Nevertheless, it has been shown, as in the study of Kirkil et al., that the questionnaire used can also influence the results in terms of diagnosis [64]. The variety of questionnaires used in the studies included in this meta-analysis can be explained by the need to adapt the questionnaire to the population studied [65-73], as is usually recommended. Regarding laboratory diagnostic techniques, it is recommended to use two complementary diagnostic tests (one very sensitive and therefore very specific) and to have the samples handed by two different technicians who do not know the clinical condition of the subject [74]. However, most of the studies included in this meta-analysis generally use only one fairly sensitive and specific diagnostic method at a time, which is not the best practice. This can be partly explained by financial constraints related to the cost of diagnostic tests, which are often quite expensive in lowincome countries, and by the nature of the sample size, which increases the burden of work. This may be 


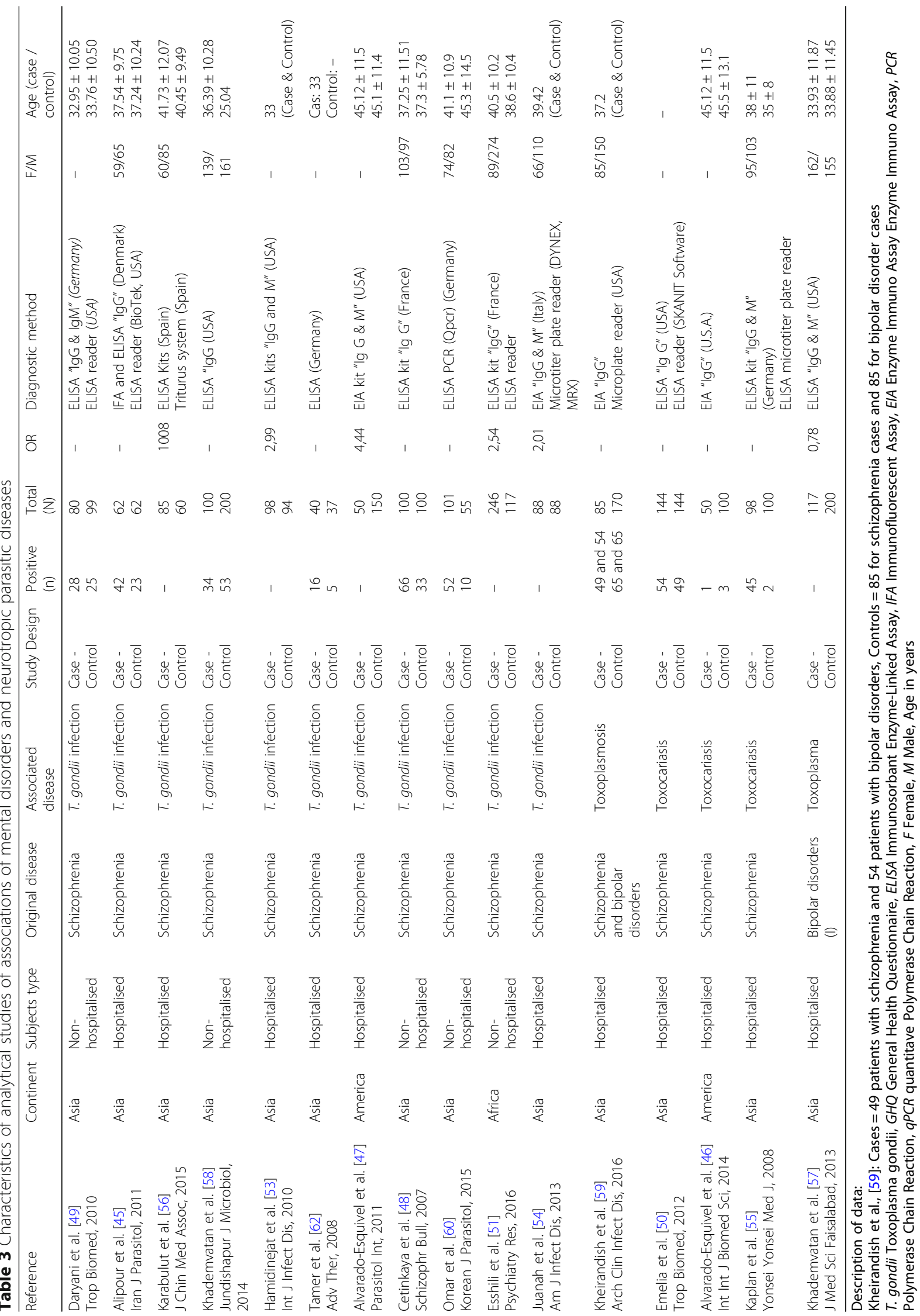




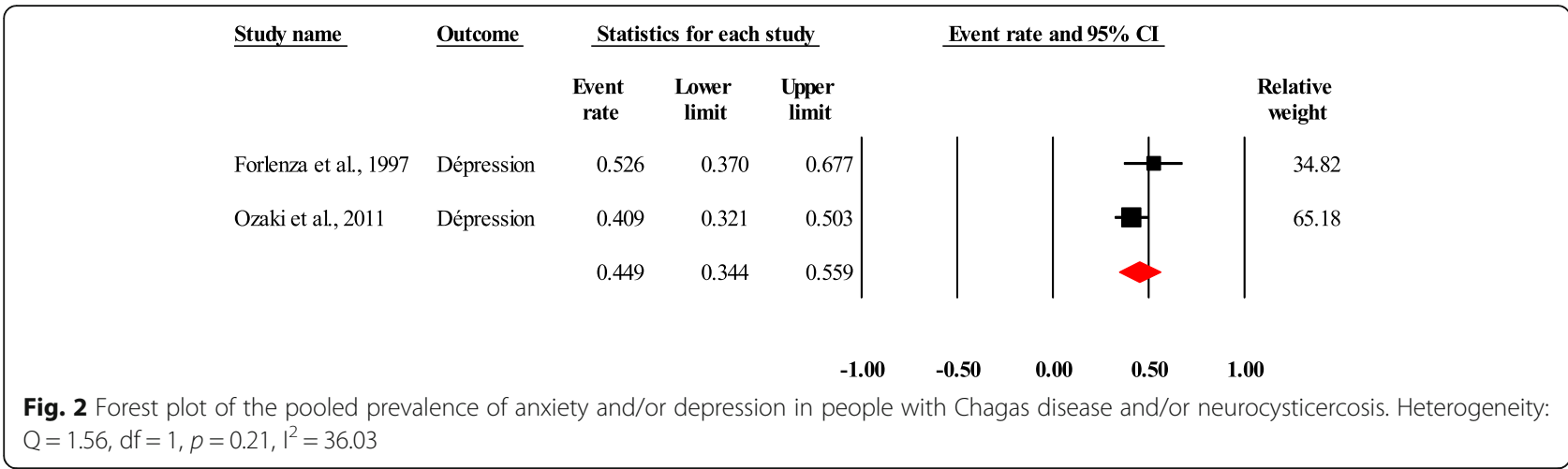

acceptable for this type of disease, since parasitic diseases are very commonly found in these countries.

The quality scores of the studies included in this meta-analysis are in line with those found by other authors [75]. There was publication bias and great heterogeneity in our estimates. In both the prevalence studies and the analytical studies, the quality scores were all largely above the average score (i.e. above half the maximum score: 11 for prevalence studies and 12.5 for casecontrol studies). But since our estimates did not change after we performed the sensitivity analysis. In our pooled estimates after withdrawing the study with the highest weight on the one hand, and the study with the lowest quality score on the other, using the two recommended methods, the sensitivity test had almost no impact on our results and the results remained robust. However, the different levels of heterogeneity found in the pooled estimates after analysis of the selected subgroups (type of original disease, type of associated disease, type of subjects included, and continent) implied that there were other covariates in play and that the latter could be the source of these heterogeneities.

This meta-analysis revealed that, despite the small number of studies included, the prevalence of anxiety

\begin{tabular}{|c|c|c|c|c|c|c|}
\hline \multirow[t]{2}{*}{ Study name } & \multirow[t]{2}{*}{ Outcome } & \multicolumn{3}{|c|}{ Statistics for each study } & \multicolumn{2}{|l|}{ Odds ratio and $95 \% \mathrm{CI}$} \\
\hline & & $\begin{array}{l}\text { Odds } \\
\text { ratio }\end{array}$ & $\begin{array}{c}\text { Lower } \\
\text { limit }\end{array}$ & $\begin{array}{c}\text { Upper } \\
\text { limit }\end{array}$ & & $\begin{array}{c}\text { Relative } \\
\text { weight }\end{array}$ \\
\hline Daryani et al., 2010 & Toxoplasmosis & 1.594 & 0.836 & 3.039 & & 6.33 \\
\hline Alipour et al., 2011 & Toxoplasmosis & 3.561 & 1.697 & 7.471 & & 5.82 \\
\hline Alvarado-Esquivel et al., 2014 & Toxocariasis & 0.660 & 0.067 & 6.510 & & 1.52 \\
\hline Cetinkaya et al., 2007 & Toxoplasmosis & 3.941 & 2.191 & 7.091 & - & 6.65 \\
\hline Emelia et al., 2012 & Toxocariasis & 1.163 & 0.718 & 1.884 & $\vdash$ & 7.20 \\
\hline Kaplan et al., 2008 & Toxocariasis & 41.604 & 9.708 & 178.297 & & 2.99 \\
\hline Khademvatan et al., 2014 & Toxoplasmosis & 1.429 & 0.850 & 2.402 & - & 7.01 \\
\hline Kheirandish et al., 2016* & Toxoplasmosis & 2.199 & 1.294 & 3.735 & $\rightarrow$ & 6.95 \\
\hline Kheirandish et al., $2016 * *$ & Toxoplasmosis & 2.814 & 1.641 & 4.825 & $\rightarrow$ & 6.90 \\
\hline Omar et al., 2015 & Toxoplasmosis & 4.776 & 2.171 & 10.507 & & 5.58 \\
\hline Tamer et al. , 2008 & Toxoplasmosis & 4.267 & 1.371 & 13.276 & & 4.02 \\
\hline Alvarado-Esquivel et al., 2011 & Toxoplasmosis & 4.440 & 1.474 & 13.370 & & 4.15 \\
\hline Esshili et al., 2016 & Toxoplasmosis & 2.540 & 1.597 & 4.040 & $\rightarrow$ & 7.30 \\
\hline Hamidinejat et al., 2010 & Toxoplasmosis & 2.990 & 1.653 & 5.410 & $\rightarrow$ & 6.62 \\
\hline Juanah et al., 2013 & Toxoplasmosis & 2.010 & 1.342 & 3.010 & $\rightarrow$ & 7.60 \\
\hline Karabulut et al., 2015 & Toxoplasmosis & 1.008 & 0.517 & 1.964 & & 6.22 \\
\hline \multirow[t]{3}{*}{ Khademvatan et al., 2013} & Toxoplasmosis & 0.780 & 0.475 & 1.280 & & 7.14 \\
\hline & & 2.329 & 1.708 & 3.177 & $<$ & \\
\hline & & & & 0.0 & 0.1 & 100 \\
\hline
\end{tabular}


Funnel Plot of Precision by Log odds ratio

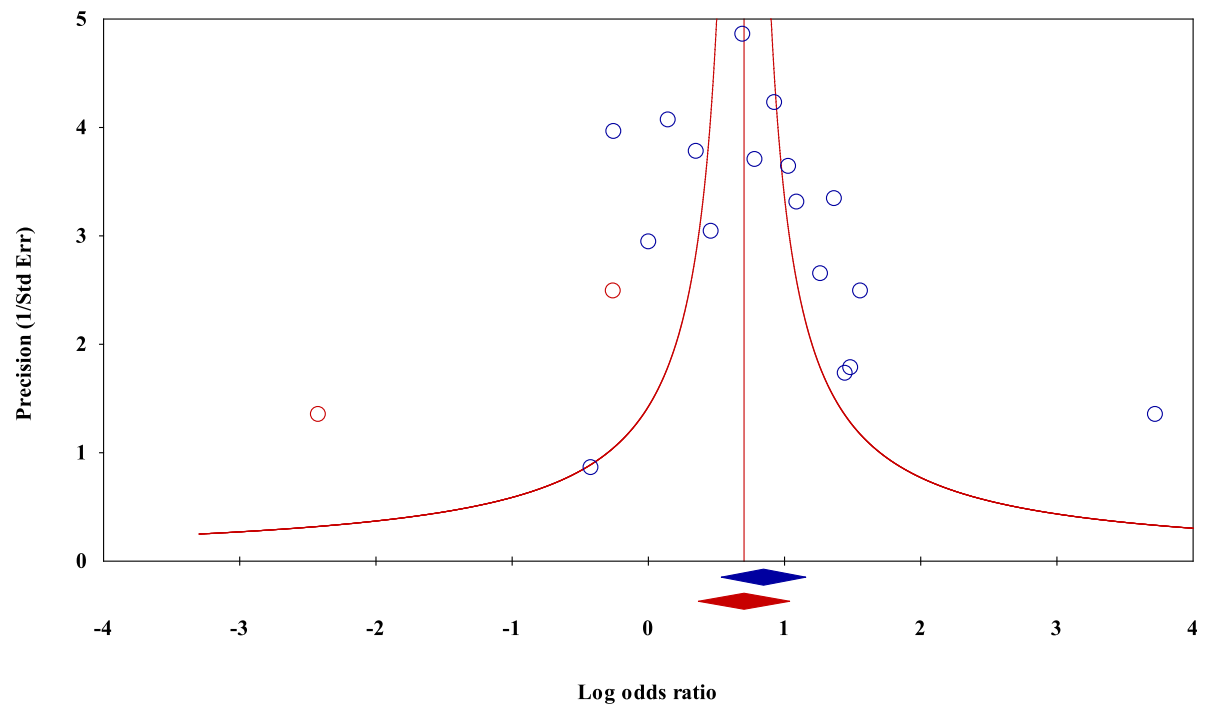

Fig. 4 Funnel plot showing found and missing analytical studies of associations of mental disorders and neurotropic parasitic diseases

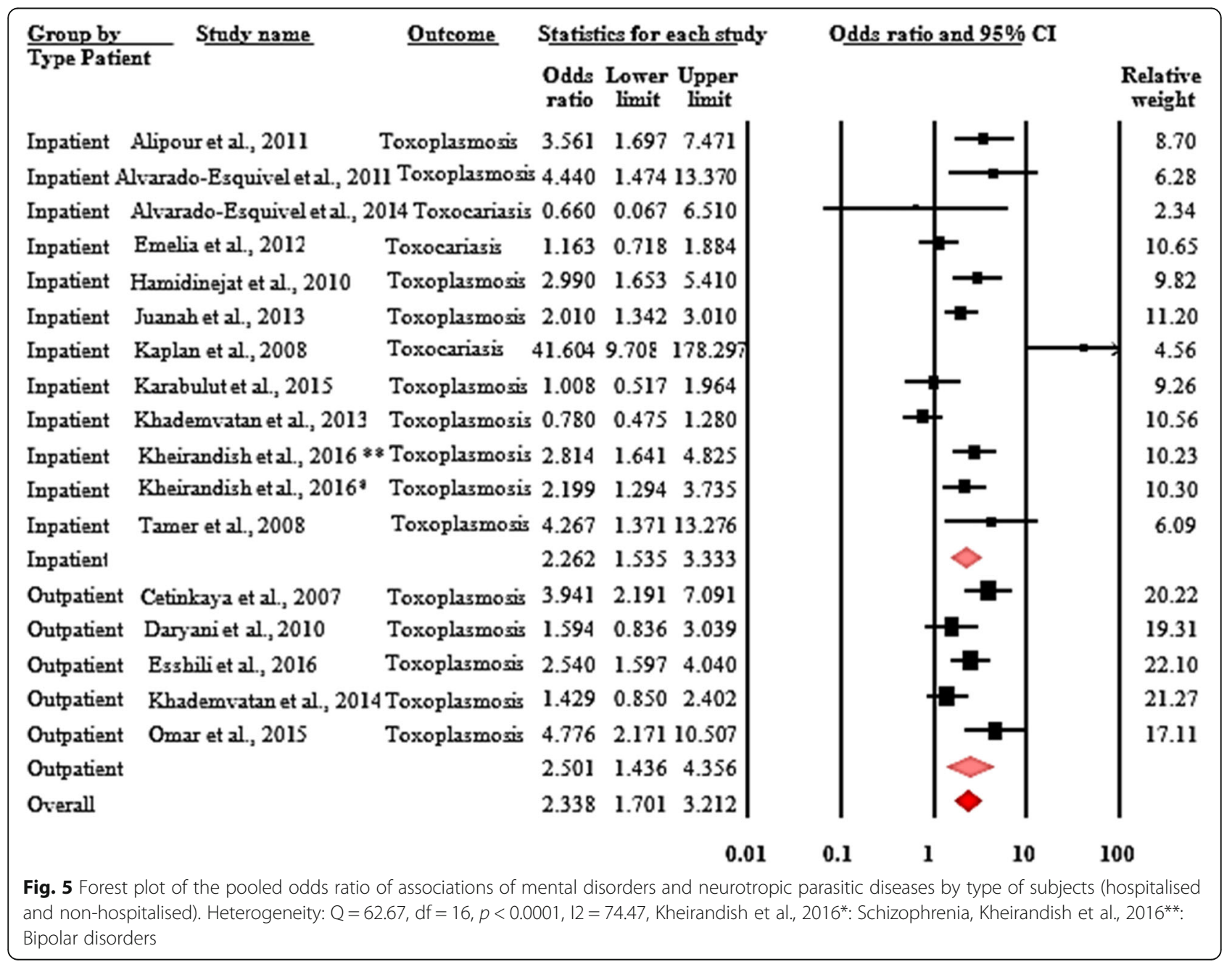


and/or depression was almost $50 \%$ in people with Chagas disease and/or neurocysticercosis. "In addition, toxocariasis and/or toxoplasmosis was associated with an increased risk of schizophrenia and/or bipolar disorders (odds ratio $=2.3$ ). More specifically, through subgroup analysis, we were able to show that toxocariasis (odds ratio $=2.7$ ) and toxocariasis and/or toxoplasmosis (odds ratio $=2.4$ ) were associated with increased risk of schizophrenia. In hospitalised subjects, the results of the subgroup analysis showed that in the presence toxocariasis and/or toxoplasmosis, the increased risk of mental disorders (schizophrenia and/or bipolar disorders) was $130 \%$, and, in non-hospitalised subjects the increased risk of mental disorders (schizophrenia and/or bipolar disorders) in presence of toxoplasmosis was $150 \%$. This similarity of results in the two types of subjects might reflect the difficulties of access to mental and neurological health care in developing and emerging countries, with mental and neurological diseases being grossly underdiagnosed, and suffering both from a low ranking in terms of public health priority.

Due to the well-known neurotropic characteristics of Toxoplasma gondii, it is commonly accepted that many psychiatric symptoms, like mental retardation, may be due to Toxoplasma gondii infections [76]. Much interest exists in determining a causative relationship between this parasite and some mental disorders, in particular schizophrenia [77] and bipolar disorders [78]. Our investigation into the presence of IgG antibodies in people with mental disorders produced results that are similar to those obtained by other authors. People living with schizophrenia were found to have a risk ratio of 1.43 to 2.73 for toxoplasmosis and/or toxocariasis [77, 79], while people with bipolar disorders were found to have a risk ratio of 1.26 to $1.52[78,79]$.

The analytical studies on the associations of mental disorders with neurotropic parasitic diseases didn't allow some statistical analyses, such as subgroup analysis. Only Asia, which accounted for most of the studies, made it possible to estimate that, in presence of toxoplasmosis and/or toxocariasis, there was a $130 \%$ increased risk of the onset of schizophrenia and/or bipolar disorders. The lack of data on mental disorders in developing and emerging countries for other continents could potentially be explained by the lack of medical consultations for people with mental disorders, and the lack of knowledge and skills regarding mental illness among primary healthcare professionals; it could also be due to the insufficient number of appropriate health centres, which, when they exist, do not seem to be accessible or have staff trained to manage mental disorders and neurotropic parasitic diseases. Religion and traditional beliefs among communities can also be additional barriers to the diagnosis of mental disorders in these countries, with these diseases often getting attributed to spiritual causes. It has been reported that up to $80 \%$ of people with mental disorders and their families might prefer to seek care from religious leaders, traditional healers or exorcist-priests [80]. Finally, poverty and the lack of national and international funding for mental health often aggravate the situation. As a result, a high proportion of people with severe mental disorders (76 to $85 \%$ ) do not receive treatment in developing and emerging countries [81].

Our results suggest that further studies on the comorbidities of mental disorders and neurotropic parasitic diseases in developing and emerging countries may be needed to highlight the true estimations of these often-neglected diseases, especially in these countries.

Despite our efforts to limit bias, our study has some limitations that were already described in our previous meta-analysis [35] which shared the same method.

The limitations of this work are related to the small sizes of the different study samples included in our pooled estimates. The fact that the identification of mental disorders was not always confirmed by a specialist in each of the studies is also a limitation. Asia, which accounted for many of the studies, could also well be an obstacle in the generalization of our results to other continents. Finally, the lack of studies meeting all inclusion criteria could be considered as a limitation in the calculation of some estimates for the co-morbidities studied.

Nevertheless, these criteria have enabled us to provide reliable and generalizable pooled estimates for these comorbidities. This meta-analysis was actually carried out according to the PRISMA 2015 guidelines and the recommendation for conducting sensitivity analyses by subtracting the study with the highest weight and the studies with the lowest quality among the studies included in each pooled estimate.

\section{Conclusion}

In this meta-analysis, the results show that the pooled estimates of co-morbidities between mental disorders and neurotropic parasitic diseases in developing and emerging countries are relatively high. Most of the included studies were conducted in Asia. In conclusion, our findings support the hypothesis that toxoplasmosis could be the cause of schizophrenia and/or bipolar disorders. We hope that this meta-analysis, the first of its kind to focus on developing and emerging countries, can provide some guidance to researchers to further explore and understand the associations between mental disorders and neurotropic parasitic diesases in developing and emerging countries. 


\section{Supplementary information}

Supplementary information accompanies this paper at https://doi.org/10. 1186/s12889-019-7933-4

Additional file 1 : Table S1. Characteristics of quality scores of prevalence studies. Global quality (Items: 1-2-3-5-6-7-9-10); External validity (Items:11-12-13); Results bias (Items: 15-16-18-20); Confusion and selection bias (Item: 25); Power (Item: 27) and S: Quality score.

Additional file $\mathbf{2}$ : Table S2. Characteristics of quality scores of analytical studies. Global quality (Items: 1-2-3-5-6-7-9-10); External validity (Items:11-12-13); Results bias (Items: 15-16-18-20); Confusion and selection bias (Item: 25); Power (Item: 27) and S: Quality score.

\section{Abbreviations}

BDI: Beck Depression Inventory; CMA: Comprehensive Meta Analysis; DSM5: Diagnostic and Statistical Manual of Mental Disorders; ElA: Enzyme Immuno Assay Enzyme Immuno Assay; ELISA: Immunosorbant EnzymeLinked Assay; GHQ: General Health Questionnaire; HAT: Human African Trypanosomiasis; ICD-10: International Classification of Diseases; IENT: Institute of Epidemiology and Tropical Neurology; IFA: Immunofluorescent Assay; MMSE: Mini Mental State Examination; MSE: Mental Status Examination; PCR: Polymerase Chain Reaction; PRISMA: Preferred Reporting Items for Systematic Review and Meta-Analysis; PSE: Present State Examination; qPCR: quantitave Polymerase Chain Reaction; SADS-L: Schedule for Affective Disorders and Schizophrenia-Lifetime

\section{Acknowledgements}

Not applicable.

\section{Authors' contributions}

PMP contributed to writing funding applications, the design of the research protocol, the validation of the studies' quality scores, the interpretation of the data, and the preparation of the manuscript. BM and FB contributed to finalizing the research protocol, data analysis, and preparation of the manuscript. VL contributed to finalizing the research protocol and preparation of the manuscript. PEB contributed to finalizing the research protocol, the evaluation of the studies' quality scores, the interpretation of the data, and the preparation of the manuscript. DG contributed to finalizing the research protocol and the preparation of the manuscript. He also contributed to writing funding applications. Finally, LOD contributed to the drafting of the research protocol, its registration in PROSPERO, the selection of articles, the evaluation of the studies' quality scores, the data analysis, the interpretation of the data, and the preparation of the manuscript. This manuscript has been read and approved by all authors.

\section{Funding}

The first author (LOB) was an intern at Sanofi for 6 months during which he received a grant. Sanofi has also provided access to its electronic databases. During his internship, LOB was supervised by VL, PEB and DG who are, or have been, Sanofi employees. VL, PEB and DG have contributed to the research protocol, the interpretation of the data and the preparation of the manuscript.

\section{Availability of data and materials}

All information generated or analyzed during this meta-analysis is available in the additional data provided by the first author.

\section{Ethics approval and consent to participate}

Not applicable.

\section{Consent for publication}

Not applicable.

\section{Competing interests}

$V L$ and PEB are Sanofi employees and own Sanofi stocks. DG is a former employee of Sanofi. All other authors declare that there is no conflict of interest related to the writing and publication of this article.

\section{Author details}

'INSERM, CHU Limoges, UMR_S 1094, Tropical Neuroepidemiology, University of Limoges, Institute of Neuroepidemiology and Tropical Neurology, CNRS FR 3503 GEIST, F-87000 Limoges, France. ${ }^{2}$ Access to Medicines, Sanofi, SAG /

CSVB, 82 AV Raspail, 94250 Gentilly, France.

Received: 19 August 2019 Accepted: 11 November 2019

Published online: 05 December 2019

\section{References}

1. World Bank: Country and Lending Groups. 2016. http://data.worldbank.org/ income-level/low-and-middle-income. Accessed 18 Sept 2016.

2. Mallewa M, Wilmshurst JM. Overview of the effect and epidemiology of parasitic central nervous system infections in African children. Semin Pediatr Neurol. 2014:21(1):19-25.

3. Steel Z, Marnane C, Iranpour C, Chey T, Jackson JW, Patel V, Silove D. The global prevalence of common mental disorders: a systematic review and meta-analysis 1980-2013. Int J Epidemiol. 2014;43(2):476-93.

4. Centers for Disease Control and prevention. National Center for Chronic Diseases Prevention and Health Promotion: Mental Health and Chronic Diseases: National Healthy Worksites (NHW); 2012. https://www.cdc.gov/ workplacehealthpromotion/tools-resources/pdfs/issue-brief-no-2-mentalhealth-and-chronic-disease.pdf. Accessed 18 Sept 2016

5. Aillon J-L, Ndetei DM, Khasakhala L, Ngari WN, Achola HO, Akinyi S, Ribero S. Prevalence, types and comorbidity of mental disorders in a Kenyan primary health Centre. Soc Psychiatry Psychiatr Epidemiol. 2014;49:1257-68.

6. Zoller T, Fèvre EM, Welburn SC, Odiit M, Coleman PG. Analysis of risk factors for T. brucei rhodesiense sleeping sickness within villages in south-east Uganda. BMC Infect Dis. 2008;8:88.

7. Okia M, Mbulamberi DB, De Muynck A. Risk factors assessment for T. b. Rhodesiense sleeping sickness acquisition in S.E. Uganda. A case-control study. Ann Soc Belg Med Trop. 1994;74:105-12.

8. Rostami A, Seyyedtabaei SJ, Aghamolaie S, Behniafar H, Lasjerdi Z, Abdolrasouli A, Mehravar S, Alvarado-Esquivel C. Seroprevalence and risk factors associated with toxoplasma gondii infection among rural communities in northern Iran. Rev Inst Med Trop Sao Paulo. 2016;58:70.

9. Nourollahpour Shiadeh M, Rostami A, Pearce BD, Gholipourmalekabadi M, Newport DJ, Danesh M, Mehravar S, Seyyedtabaei SJ. The correlation between toxoplasma gondii infection and prenatal depression in pregnant women. Eur J Clin Microbiol Infect Dis. 2016;35:1829-35.

10. Flegr J. Predictors of toxoplasma gondii infection in Czech and Slovak populations: the possible role of cat-related injuries and risky sexual behavior in the parasite transmission. Epidemiol Infect. 2017;145:1351-62.

11. Vigo D, Thornicroft G, Atun R. Estimating the true global burden of mental illness. Lancet Psychiatry. 2016;3:171-8.

12. Blakemore A, Dickens C, Guthrie E, Bower P, Kontopantelis E, Afzal C, Coventry PA. Depression and anxiety predict health-related quality of life in chronic obstructive pulmonary disease: systematic review and meta-analysis. Int J Chron Obstruct Pulmon Dis. 2014;9:501-12.

13. Elsheikha HM, Büsselberg D, Zhu X-Q. The known and missing links between toxoplasma gondii and schizophrenia. Metab Brain Dis. 2016;31: 749-59.

14. World Health Organization. World Health Report 2001 - Mental Health: New Design, New Hope. Geneva: WHO; 2001. p. 172. WHO library; http://www. who.int/whr/2001/media centre/press_release/fr/. Accessed 13 Sept 2017

15. World Health Organization: Chapter 2: Impact of mental and behavioural disorders. http://www.who.int/whr/2001/chapter2/fr/index5.html. Accessed 24 Apr 2017.

16. Haute Autorité de Santé: Guidance Note. Multi-annual programme on psychiatry and mental health. 2013. http://www.has-sante.fr/portail/upload/ docs/application/pdf/2014-01/2013_10_08_programme_sante_mentale_ college.pdf. Accessed 24 Apr 2017.

17. World Health Organization. World Malaria Report 2015. Geneva: WHO library; 2015. p. 280. http://www.who.int/malaria/publications/world-malariareport-2015/report/en/. Accessed 13 Mar 2019

18. Institut Pasteur. Chagas disease: Institut Pasteur; 2015. https://www.pasteur. $\mathrm{fr} / \mathrm{fr} /$ centre-medical/fiches-maladies/maladie-chagas. Accessed 23 Apr 2017

19. Nicoletti A. Chapter 16 - Toxocariasis. In: Hector H, editor. Garcia HBTaOHDB Handbook of Clinical Neurology, vol. 114. Amsterdam: Elsevier; 2013. p. 217-28.

20. Magnaval JF, Glickman LT, Dorchies P, Morassin B. Highlights of human toxocariasis. Korean J Parasitol. 2001;39:1-11. 
21. Kenny JV, MacCabe RJ, Smith HV, Holland C. Serological evidence for the presence of toxocariasis in the Turkana District of Kenya. Trans R Soc Trop Med Hyg. 1995;89:377-8.

22. Chieffi PP, Ueda M, Camargo ED, de Souza AM, Guedes ML, Gerbi LJ, Spir M, Moreira AS. Visceral larva migrans: a seroepidemiological survey in five municipalities of São Paulo state, Brazil. Rev Inst Med Trop Sao Paulo. 1990; 32:204-10.

23. Damian MM, Martins M, Sardinha JF, De S, Chaves A, Tavares ADM. Frequency of the antibody anti-Toxocara canis in a community along the Uatumã River, state of Amazonas. Rev Soc Bras Med Trop. 2007:40:661-4.

24. Park HY, Lee SU, Huh S, Kong Y, Magnaval JF. A seroepidemiological survey for toxocariasis in apparently healthy residents in Gangwon-do, Korea. Korean J Parasitol. 2002:40:113-7.

25. Hayashi E, Tuda J, Imada M, Akao N, Fujita K. The high prevalence of asymptomatic Toxocara infection among schoolchildren in Manado, Indonesia. Southeast Asian J Trop Med Public Health. 2005;36:1399-406.

26. SANOFI. Sanofi's commitment to the fight against sleeping sickness: Le Hub; 2017. https://lehub.sanofi.com/fr/acces-aux-soins/maladie-du-sommeil/. Accessed 24 Apr 2017

27. Bouteille B. Epidemiology of cysticercosis and neurocysticercosis. Med Sante Trop. 2014:24:367-74.

28. World Health Organization. Working to overcome the global impact of neglected tropical diseases: first WHO report on neglected tropical diseases. Geneva: Department of Reproductive health and Research, World Health Organization; 2010.

29. Alvarado-Esquivel C. Toxocara infection in psychiatric inpatients: a case control Seroprevalence study. PLoS One. 2013;8:e62606.

30. Cong W, Zhang X-X, Zhou N, Yu C-Z, Chen J, Wang X-Y, Li B, Qian A-D, Zhu $X-Q$. Toxocara Seroprevalence among clinically healthy individuals, pregnant women and psychiatric patients and associated risk factors in Shandong Province, eastern China. PLoS Negl Trop Dis. 2014;8:e3082.

31. Abdoli A, Dalimi A, Arbabi M, Ghaffarifar F. Neuropsychiatric manifestations of latent toxoplasmosis on mothers and their offspring. J Matern Fetal Neonatal Med. 2014;27:1368-74.

32. Forlenza OV, Vieira Filho AH, Machado LR, Nóbrega JP, de Barros NG. Depressive disorders associated with neurocysticercosis: prevalence and clinical correlations. Arq Neuropsiquiatr. 1998;56:45-52.

33. Ramírez-Bermudez J, Corona T. Neuropsiquiatic manifestation in cerebral cysticercosis. Archivos de Neurociencias. 2005;10:92-4.

34. Wiwanitkit V. Dementia and neurocysticercosis. Acta Neurol Taiwanica. 2014; 23:1-3.

35. Daré LO, Bruand P-E, Gérard D, Marin B, Lameyre $V$, Boumédiène F, Preux PM. Co-morbidities of mental disorders and chronic physical diseases in developing and emerging countries: a meta-analysis. BMC Public Health. 2019;19(1):304

36. Stroup DF, Berlin JA, Morton SC, Olkin I, Williamson GD, Rennie D, Moher D, Becker BJ, Sipe TA, Thacker SB. Meta-analysis of observational studies in epidemiology: a proposal for reporting. Meta-analysis of observational studies in epidemiology (MOOSE) group. JAMA. 2000;283:2008-12.

37. Moher D., Shamseer L., Ghersi D., Liberati A., Petticrew M., Shekelle P., et al. PRISMA for systematic review protocols (PRISMA-P). http://prisma-statement. org/Extensions/Protocols.aspx. Accessed 30 Oct 2016.

38. National Collaborating Centre for Methods and Tools: Quality Checklist for Health Care Intervention Studies. Hamilton, On : McMaster University : Metaanalysis in medical research. 2008. http://www.nccmt.ca/resources/search/9. Accessed 23 Mar 2017.

39. Downs SH, Black N. The feasibility of creating a checklist for the assessment of the methodological quality both of randomised and non-randomised studies of health care interventions. J Epidemiol Community Health. 1998; 52:377-84.

40. CMA Manuals: Comprehensive Meta-Analysis Software. 2017. https://www. meta-analysis.com/pages/cma_manual.php. Accessed 31 Mar 2017.

41. Borenstein M, Hedges LV, Higgins JP, Rothstein HR. Introduction to MetaAnalysis. Oxford: Wiley; 2009.

42. Boyle MH. Guidelines for evaluating prevalence studies. Evid Based Mental Health. 1998;1:37-9.

43. Borenstein $M$, Hedges LV, Higgins JPT, Rothstein HR. A basic introduction to fixed-effect and random-effects models for meta-analysis. Res Synth Methods. 2010;1:97-111.

44. Egger M, Davey Smith G, Schneider M, Minder C. Bias in meta-analysis detected by a simple, graphical test. BMJ. 1997;315:629-34.
45. Alipour A, Shojaee S, Mohebali M, Tehranidoost M, Abdi Masoleh F, Keshavarz H. Toxoplasma infection in schizophrenia patients: a comparative study with control group. Iran J Parasitol. 2011;6:31-7.

46. Alvarado-Esquivel C, Hernández-Tinoco J, Sánchez-Anquiano LF, CisnerosMartínez JA. Low seroprevalence of Toxocara infection in schizophrenic inpatients in Durango, Mexico: a case control study. Int J Biomed Sci. 2014; 10:269-71.

47. Alvarado-Esquivel C, Urbina-Álvarez JD, Estrada-Martínez S, Torres-Castorena A, Molotla-de-León G, Liesenfeld O, Dubey JP. Toxoplasma gondii infection and schizophrenia: a case control study in a low toxoplasma seroprevalence Mexican population. Parasitol Int. 2011;60:151-5.

48. Cetinkaya Z, Yazar S, Gecici O, Namli MN. Anti-toxoplasma gondii antibodies in patients with schizophrenia--preliminary findings in a Turkish sample. Schizophr Bull. 2007;33:789-91.

49. Daryani A, Sharif M, Hosseini SH, Karimi SA, Gholami S. Serological survey of toxoplasma gondii in schizophrenia patients referred to psychiatric hospital, Sari City, Iran. Trop Biomed. 2010;27:476-82.

50. Emelia O, Amal RN, Ruzanna ZZ, Shahida H, Azzubair Z, Tan KS, Noor Aadila S, Siti NM, Aisah MY. Seroprevalence of anti-toxoplasma gondii lgG antibody in patients with schizophrenia. Trop Biomed. 2012;29:151-9.

51. Esshili A, Thabet $S$, Jemli A, Trifa F, Mechri A, Zaafrane F, Gaha L, Juckel G, Babba H, Bel Hadj Jrad B. Toxoplasma gondii infection in schizophrenia and associated clinical features. Psychiatry Res. 2016;245:327-32.

52. Forlenza OV, Filho AH, Nobrega JP, dos Ramos ML, de Barros NG, de Camargo $\mathrm{CH}$, da Silva MF. Psychiatric manifestations of neurocysticercosis: a study of 38 patients from a neurology clinic in Brazil. J Neurol Neurosurg Psychiatry. 1997;62:612-6.

53. Hamidinejat $H$, Ghorbanpoor M, Hosseini H, Alavi SM, Nabavi L, Jalali MHR, Borojeni MP, Jafari H, Mohammadaligol S. Toxoplasma gondii infection in first-episode and inpatient individuals with schizophrenia. Int J Infect Dis. 2010;14:e978-81.

54. Juanah LY, Jalaludin J, Osman M, Osman ZJ. Seroprevalence of toxoplasma Gondii among schizophrenics at hospital Kajang. Am J Infect Dis. 2013;9:116.

55. Kaplan M, Kalkan A, Kuk S, Demirdag K, Ozden M, Kilic SS. Toxocara seroprevalence in schizophrenic patients in Turkey. Yonsei Med J. 2008;49: 224-9.

56. Karabulut N, Bilgiç S, Gürok MG, Karaboğa F. Is there any role of latent toxoplasmosis in schizophrenia disease? J Chin Med Assoc. 2015;78:533-7.

57. Khademvatan S, Khajeddin N, Izadi S, Saki J. Study of toxoplasma gondii infection in patients with bipolar disorder. J Med Sci (Faisalabad). 2013;13: 215-20.

58. Khademvatan S, Saki J, Khajeddin N, Izadi-Mazidi M, Beladi R, Shafiee B, Salehi Z. Toxoplasma gondii exposure and the risk of schizophrenia. Jundishapur J Microbiol. 2014;7:e12776.

59. Kheirandish F, Nazari H, Mahmoudvand H, Yaseri Y, Tarahi MJ, Fallahi S, Ezatpour B. Possible link between toxoplasma gondii infection and mood disorders in Lorestan province, Western Iran. Arch Clin Infect Dis. 2016;1 1:1-8.

60. Omar A, Bakar OC, Adam NF, Osman H, Osman A, Suleiman AH, Manaf MRA Selamat MI. Seropositivity and serointensity of toxoplasma gondii antibodies and DNA among patients with schizophrenia. Korean J Parasitol. 2015;53: 29-34.

61. Ozaki Y, Guariento ME, de Almeida EA. Quality of life and depressive symptoms in Chagas disease patients. Qual Life Res Int J Qual Life Asp Treat Care Rehab. 2011;20:133-8

62. Tamer GS, Dundar D, Yalug I, Caliskan S, Yazar S, Aker A. The schizophrenia and toxoplasma gondii connection: infectious, immune or both? Adv Ther. 2008;25:703-9.

63. Stolic RV, Trajkovic GZ, Mihailovic B, Sipic MV, Celic DB, Lazic SF, Nikolic GR, Sovtic SR, Stolic DZ. Characteristics of depression in obese people living in an insecure environment. Indian J Med Sci. 2010;64:307-14.

64. Kirkil G, Deveci F, Deveci SE, Atmaca M. Anxiety and depression symptoms in patients with chronic obstructive pulmonary disease (copd). Klinik Psikofarmakoloji Bulteni. 2015;25:151-61.

65. Aghanwa HS, Erhabor GE. Specific psychiatric morbidity among patients with chronic obstructive pulmonary disease in a Nigerian general hospital. J Psychosom Res. 2001;50:179-83.

66. Fanger PC, Azevedo RCS, Mauro MLF, Lima DD, Gaspar KC, Silva VF, Nascimento WTJ, Botega NJ. Depression and suicidal behavior of cancer inpatients: prevalence and associated factors. Rev Assoc Med Bras (1992). 2010;56:173-8. 
67. Hong JS, Tian J. Prevalence of anxiety and depression and their risk factors in Chinese cancer patients. Support Care Cancer. 2014;22:453-9.

68. Huang Y, Chen J, Yang J, Song K, Wang X, Cheng X, Qu S. Evaluation of depressive symptoms in obese patients with or without acanthosis nigricans. Hormones (Athens, Greece). 2015;14:417-24.

69. Islam SMS, Ferrari U, Seissler J, Niessen L, Lechner A. Association between depression and diabetes amongst adults in Bangladesh: a hospital based case-control study. J Glob Health. 2015;5:020406.

70. Mollaoglu H, Ucok K, Kaplan A, Genc A, Mayda H, Guzel HI, Sener U, Uygur E, Ozbulut O. Association analyses of depression, anxiety, and physical fitness parameters in Turkish obese adults. J Back Musculoskelet Rehabil. 2012;25:253-60.

71. Negi H, Sarkar M, Raval AD, Pandey K, Das P. Presence of depression \& its risk factors in patients with chronic obstructive pulmonary disease. Indian J Med Res. 2014:139:402-8.

72. Yildirim A, Hacihasanoğlu Aşilar R, Bakar N, Demir N. Effect of anxiety and depression on self-care agency and quality of life in hospitalized patients with chronic obstructive pulmonary disease: a questionnaire survey. Int J Nurs Pract. 2013;19:14-22.

73. Zhao L, Li X, Zhang Z, Song C, Guo C, Zhang Y, Zhang Y, Li L, Lu G, Zheng $G$, et al. Prevalence, correlates and recognition of depression in Chinese inpatients with cancer. Gen Hosp Psychiatry. 2014;36:477-82.

74. World Health Organization. Good Laboratory Practice: Quality Practices for Regulated Non-clinical Research and Development. Geneva: WHO library; 2010. p. 232.

75. Amerio A, Stubbs B, Odone A, Tonna M, Marchesi C, Nassir Ghaemi S. Bipolar I and II disorders; a systematic review and Meta-analysis on differences in comorbid obsessive-compulsive disorder. Iran J Psychiatry Behav Sci. 2016;10:e3604.

76. Zhu S, Guo M-F, Feng Q-C, Fan J-M, Zhang L-X. Epidemiological evidences from China assume that psychiatric-related diseases may be associated with toxoplasma gondii infection. Neuroendocrinol Lett. 2007;28:115-20.

77. Arias I, Sorlozano A, Villegas E, de Dios LJ, McKenney K, Cervilla J, Gutierrez B, Gutierrez J. Infectious agents associated with schizophrenia: a metaanalysis. Schizophr Res. 2012;136:128-36.

78. de Barros JLVM, Barbosa IG, Salem H, Rocha NP, Kummer A, Okusaga OO, Soares JC, Teixeira AL. Is there any association between toxoplasma gondii infection and bipolar disorder? A systematic review and meta-analysis. J Affect Disord. 2017:209:59-65.

79. Sutterland AL, Fond G, Kuin A, Koeter MWJ, Lutter R, van Gool T, Yolken R, Szoke A, Leboyer M, de Haan L. Beyond the association. Toxoplasma gondii in schizophrenia, bipolar disorder, and addiction: systematic review and meta-analysis. Acta Psychiatr Scand. 2015;132:161-79.

80. Toftegaard KL, Gustafsson LN, Uwakwe R, Andersen UA, Becker T, Bickel GG, Bork B, Cordes J, Frasch K, Jacobsen BA, et al. Where are patients who have co-occurring mental and physical diseases located? Int J Soc Psychiatry. 2015;61:456-64.

81. World Health Organization. Mental Health Action Plan 2013-2020. Geneva: WHO Library Cataloguing-in-Publication Data; 2013. p. 50.

\section{Publisher's Note}

Springer Nature remains neutral with regard to jurisdictional claims in published maps and institutional affiliations.

Ready to submit your research? Choose BMC and benefit from:

- fast, convenient online submission

- thorough peer review by experienced researchers in your field

- rapid publication on acceptance

- support for research data, including large and complex data types

- gold Open Access which fosters wider collaboration and increased citations

- maximum visibility for your research: over $100 \mathrm{M}$ website views per year

At BMC, research is always in progress.

Learn more biomedcentral.com/submissions 